NOTICE: this is the author's version of a work that was accepted for publication in Human Movement Science. Changes resulting from the publishing process, such as peer review, editing, corrections, structural formatting, and other quality control mechanisms may not be reflected in this document. Changes may have been made to this work since it was submitted for publication. A definitive version was subsequently published in Human Movement Science, Vol. 38 (2014). DOI: 10.1016/j.humov.2014.08.004 


\title{
A comparison of the upper limb movement kinematics utilized by children playing virtual and real table tennis
}

\author{
Amy Bufton ${ }^{1}$ \\ Dr. Amity Campbell PhD ${ }^{1}$ \\ Dr. Erin Howie PhD ${ }^{1}$ \\ Prof. Leon Straker $\mathbf{P h D}^{1}$
}

${ }^{1}$ School of Physiotherapy and Exercise Science, Curtin University, Perth, Western Australia

Address correspondence to:

Leon Straker

School of Physiotherapy and Exercise Science

Curtin University

GPO Box U1987 Perth,

Western Australia, 6845

Tel: (+61) 0892263634

Email: L.Straker@curtin.edu.au 


\begin{abstract}
Active virtual games (AVG) may facilitate gross motor skill development, depending on their fidelity. This study compared the movement patterns of nineteen 10-12yr old children, whilst playing table tennis on three AVG consoles (Nintendo Wii, Xbox Kinect, Sony Move) and as a real world task. Wrist and elbow joint angles and hand path distance and speed were captured. Children playing real table tennis had significantly smaller (e.g. Wrist Angle Forehand Real-Kinect: Mean Difference (MD): $-18.2^{\circ}, 95 \%$ Confidence Interval (CI): -26.15 to -10.26) or slower (e.g. Average Speed Forehand Real-Kinect: MD: $-1.98 \mathrm{~m} . \mathrm{s}^{-1}$, $95 \%$ CI: 2.35 to -1.61) movements than when using all three AVGs. Hand path distance was smaller in forehand and backhand strokes (e.g. Kinect-Wii: MD: 0.46 m, $95 \%$ CI: 0.13 to 0.79 ) during playing with Kinect than Move and Wii. The movement patterns when playing real and virtual table tennis were different and this may impede the development of real world gross motor skills. Several elements, including display, input and task characteristics, may have contributed to the differences in movement patterns observed. Understanding the interface components for AVGs may help development of higher fidelity games to potentially enhance the development of gross motor skill and thus participation in PA.
\end{abstract}

Keywords: virtual games, movement patterns, gross motor skill, fidelity

\title{
Highlights:
}

- Hand and arm movements differ between virtual and real table tennis play

- Hand and arm movements also differ between Kinect, Move and Wii table tennis play

- Virtual reality game interfaces influence movement fidelity 


\section{Introduction}

Regular participation in physical activity (PA) is important for children's health and development - improving bone mineral density (Janz et al., 2010), reducing the risk of obesity, improving cardiovascular function, providing psychological benefits (Australian Government: Department of Health and Ageing 2010) and enhancing the development of gross motor skills (McKenzie, Alcaraz, \& Sallis, 1998). Reduced participation in PA can lead to poorer gross motor skills which in turn can lead to reduced confidence and motivation to participate in PA (McKenzie, et al., 1998), Conversely, poor motor skills during childhood have been associated with physical inactivity in adults (Lloyd, Saunders, Bremer, \& Tremblay, 2014), thus creating a vicious cycle of physical inactivity and poor motor skills (Straker et al., 2011). As a result of this symbiotic relationship between motor skills and PA participation, there is an urgent need to develop motor skill proficiency in all children (L. M. Barnett et al., 2013). Physical education in schools has traditionally been used to develop motor proficiency in children, though physical education alone may no longer afford adequate opportunities for skill development (Barnett et al. 2013). Thus, alternative opportunities for motor skill development are needed.

Electronic games are played by the majority of children. For example $85 \%$ of Australian 5-14 yr olds played electronic games outside of school hours (Australian Bureau of Statistics [ABS] 2012) and 87\% of American households owned some form of electronic game (Rideout, Foehr, \& Roberts, 2010). American 8- to 18- year olds spend an average of 1 hour and 13 minutes playing electronic games each day (Rideout, et al., 2010) and there has recently been a large increase in the time children spend playing electronic games $(\sim 300 \%$ increase from 1999 to 2009) (Rideout, et al., 2010). Traditional sedentary games require only key pressing for game play and there is concern that the substantial and growing exposure to these sedentary games is displacing real world PA and thus contributing to the aforementioned vicious cycle of poor gross motor skill and low PA (Straker, et al., 2011). However, a new generation of electronic games requires large body movements during play and may provide an alternative opportunity for motor skill development (Papastergiou, 2009). Active virtual reality games (AVGs), played on commercially available consoles such as Nintendo Wii (Kyoto, Japan), Microsoft Xbox Kinect (Redmond, USA), and Sony Move (Tokyo, Japan) are currently popular. One benefit of AVGs is they are generally accepted as motivational for children, which in turn might lead to regular play and increased repetition of 
motor skill practice (Levac et al., 2010). It is largely assumed that this AVG training will lead to real world skill improvement (Rose et al., 2000). However, limited research exists on how motor skills during AVG play may transfer to real world skills.

Transfer of learning is a widely utilised principle relating to education, rehabilitation and skill acquisition. Contradictory theoretical interpretations of the cognitive process associated with transfer have been posited (Newell, 1989; Thorndike \& Woodworth, 1901). However, in the case of skill acquisition, the importance of 'task constraints' is highlighted across multiple theories (K Davids, C. Button, \& S. Bennett, 2008b; Newell, 1989). For example, the dynamic systems theory suggests that motor skill development is a non-linear process, involving movement systems, in response to individual, environmental and task constraints (K Davids, C Button, \& S Bennett, 2008a). In the context of task transfer, as the constraints vary, the performer will adapt their movement in order to achieve the same desired outcome (Davids, et al., 2008b). One way to assess the similarity of constraints is the individual's resulting behavior (Ackerman \& Cianciolo, 2002). Therefore the fidelity of the constraints in an AVG could be assessed by comparing the resulting movement pattern with a real world task.

The specificity of training principle supports that improvement will arise from repetition of a similar movement (M. L. Barnett, Ross, Schmidt, \& Todd, 1973). It is proposed that performance will be optimal when the task acquisition and later repeated task performance are similar in terms of task constraints (M. L. Barnett, et al., 1973; Newell, 1989). Several studies have demonstrated that regular use of Wii Fit can improve measures of motor performance in children with balance impairment and cerebral palsy (D. Jelsma, Geuze, Mombarg, \& Smits-Engelsman, 2014; J. Jelsma, Pronk, Ferguson, \& Jelsma-Smit, 2013). It is unknown whether typically developing children may successfully train motor skills using commercially available AVG and the large range of games that currently replicate physical world sporting games. Additionally, no study to date has measured the movement kinematics during AVG play and how they differ from the real world. Understanding the difference in movement patterns required between $\mathrm{AVG}$ and the real world will help to facilitate the development of effective and efficient clinical and physical education applications to improve motor skills in children. 
Despite the diverse theories hypothesing the specific underlying mechanism behind skill transfer, it is well supported that AVGs should replicate authentic environmental and task constraints as closely as possible (M. L. Barnett, et al., 1973), i.e. have high fidelity. There are a number of modifiable and non-modifiable constraints associated with AVG fidelity. Non-modifiable fidelity constraints (such as not actually striking a ball) may result in measureable differences in movement patterns. Modifiable aspects, such as display characteristics and input control device, currently differ between consoles. For example, the Move and Wii include remote input devices, while the Kinect inputs directly from player movement. Different movement kinematics may therefore be required by the different AVG consoles. Identifying the AVG console that best replicates real world movements will guide future applications for the purpose of motor skill training.

If AVGs do not provide adequate constraint fidelity, they will not ameliorate the poor motor skill proficiency and low PA participation cycle, and may contribute to its perpetuation. Therefore, the aim of this study was to compare the movement kinematics used by children playing table tennis in a virtual world using different AVGs with the movement kinematics used when playing table tennis in the real physical world. The primary aim was to compare upper limb kinematics of children playing table tennis in a digital game to physical world table tennis. The secondary aim was to compare the movement kinematics during table tennis play on three different AVG consoles.

\section{Method}

\section{1 Design}

This study used a repeated measures design to compare the upper limb movement kinematics of children playing real world table tennis and table tennis on three AVGs.

\subsection{Participants}

Nineteen children [mean (standard deviation) height: $144.1 \mathrm{~cm}(8.4)$ and weight $40.2 \mathrm{~kg}$ (10.3), 9 males] were recruited by community notices and networks. Inclusion criteria were that children had to be 10-12 yrs old, have normal or adequately corrected vision and hearing, and be English-speaking. This age group was selected as they can independently comprehend instructions and are at the age of peak electronic game use (Rideout et al 2010). Equal numbers of males and females were sought. Potential participants would have been excluded 
if they had any developmental, musculoskeletal or neurological disorder, or poor motor coordination (below the $16^{\text {th }}$ percentile Movement Assessment Battery for Children-Second Edition (MABC-2) (Henderson, Sugden, \& Barnet, 2007).

Participants were able to withdraw at any time without prejudice. No participants withdrew from the study. Assent/consent was acquired from each child and their parent or guardian. The project was approved by Curtin University Human Research Ethics Committee (PT215/2013).

\subsection{Variables}

The independent variable was 'table tennis type' with four types; Real, Kinect, Move and Wii. Real table tennis was performed using a standard table tennis table, bat and balls. The Xbox Kinect (Microsoft, Redmond, USA) tracks body movement via image contrast and requires no hand held sensor. Participants played the table tennis game from Kinect Sports (Microsoft, Redmond, USA). The Sony Playstation Move (Sony, Tokyo, Japan) uses a camera and a hand held 'wand' with movement sensors to track the position and orientation of the 'wand' sensor. Participants played the table tennis game from Sony Move Sports Champions (Sony, Tokyo, Japan). The Nintendo Wii (Nintendo, Kyoto, Japan) uses infrared detection and a hand held 'remote' with movement sensors to track the motion and orientation of the 'remote' sensor. Participants played the table tennis game from Wii Sports Resort (Nintendo, Kyoto, Japan).

A 14 camera three-dimensional motion analysis system (Vicon Industries Inc, Hauppauge, USA), sampling at $250 \mathrm{~Hz}$ was utilized to capture dominant upper limb motion during table tennis play. The cameras tracked the position of the retro-reflective markers in threedimension and this system has demonstrated a reconstruction error of $<1 \mathrm{~mm}$ (Ehara, Fujimoto, Miyazaki, Tanaka, \& Yamamoto, 1995; Richards, 1999). Participants were therefore fitted with a set of retro-reflective body markers on their preferred hand, forearm and upper arm in accordance with the calibrated anatomical systems technique, as previously described (Campbell \& Alderson, 2009; Campbell \& Lloyd, 2009; Mitchinson, Campbell, Oldmeadow, Gibson, \& Hopper, 2012; Wu et al., 2005). A single static subject calibration trial was required to record the location of the anatomical landmarks (wrist and elbow epicondyles) (Cappozzo, Catani, Croce, \& Leardini, 1995). 


\subsection{Procedures}

For each table tennis type, participants practiced for 5 points during which time they were given encouragement and technique feedback. Participants then played a match to 11 points, with no technique feedback or instruction from the researcher. Participants played against a computer generated opponent for the AVG and against the same researcher $(\mathrm{AB})$ for the Real condition. As participants also performed a series of other tasks on the different consoles, the order of table tennis type (Kinect, Move, Wii and Real) was standardised, to minimize participant time burden and overall fatigue. The whole data collection entailed about 90 minutes for each participant.

\subsection{Data Processing}

Three forehand and three backhand strokes were randomly identified from the match play on each table tennis type (Kinect, Move, Wii and Real). A forehand stroke was defined as beginning with the palm facing away from the body, and upper arm positioned on their preferred side of their body. A backhand stroke was defined as beginning with the palm facing toward the body and preferred upper limb on their non-preferred side of the body. Each stroke was determined as the point from the back swing where the forward movement was initiated to the point in the forward swing when the forward movement ceased.

The Vicon nexus data processing included the utilization of standard biomechanics procedures, including cubic spline interpolation, to correct marker trajectory breaks of less than 20 frames. Trials with breaks larger than 20 frames were not analysed. Two participants (1 male) were excluded due to poor quality of data (i.e. trials with marker breaks frequently greater than 20 frames). The data were filtered using a mean square error of 3 , as determined from a residual analysis (Woltering, 1986). A validated mathematical model (Campbell \& Alderson, 2009; Campbell \& Lloyd, 2009) was used to calculate hand, wrist and elbow kinematics. Finally, the dependent wrist and elbow kinematic variables were output using a customized LabView program (National Instruments, Austin, U.S.A) including; hand path distance, duration, average speed, maximum speed and time of maximum speed, along with wrist and elbow peak flexion, extension and range.

\subsection{Statistical Analysis}

Data were inspected for outliers and standard parametric assumptions checked (e.g normal distribution). A series of repeated measures analyses of variance were performed using SPSS 
(version 21) to detect any main effect of table tennis type. Pair-wise comparisons were used to identify differences between table tennis types. Backhand and forehand strokes were analysed separately. A critical alpha level of 0.01 was used to minimise type 1 and type 2 errors.

\section{Results}

\subsection{Wrist Angles}

There was a significant effect of 'table tennis type' on wrist range in both the forehands and backhands (Table 1). The pair wise comparisons revealed that the Real table tennis typically had a significantly smaller range than all three AVGs for forehands and backhands. There was no significant difference in wrist angle range within AVGs for forehands or backhands.

Insert Table 1 here

Real table tennis forehands typically had a significantly smaller wrist angle maximum than all three virtual gaming consoles. For backhands, it was found that Real wrist angle maximum was significantly less than Move. There was no significant difference in wrist angle maximum between AVGs for forehands or backhands.

There was no significant difference in wrist angle minimum between the four 'table tennis types' for forehands. For backhand wrist angle minimum Real was found to be significantly less than Move and Kinect. There was no significant difference for wrist angle minimum between AVGs for backhands.

Insert Figure 1 here

\subsection{Elbow Angles}

There was a significant main effect of 'table tennis type' on elbow range in both forehands and backhands (Table 2). The pair wise comparisons revealed that Real table tennis typically had a significantly smaller range than all three AVGs for forehands and backhands. There was no significant difference in elbow angle range within AVGs for forehands or backhands.

Insert Table 2 here 
There was no significant difference in elbow angle maximum between the four 'table tennis types' for forehands and backhands.

For elbow angle minimum for forehands Kinect was significantly less than Wii and Real. There was no significant difference for forehand elbow minimum between Wii-Move, RealMove and Real-Wii. Real table tennis typically had a significantly larger elbow angle minimum than all three AVGs for backhands. For backhands Kinect had a significantly smaller elbow angle minimum than the other three 'table tennis types'.

Insert Figure 2 here

\subsection{Hand Path Temporal and Spatial Characteristics}

There was a significant main effect for 'table tennis type' on hand path distance in both forehands and backhands (Table 3 and Figure 3a). The pair wise comparisons revealed that Real table tennis typically had a significantly smaller hand path distance than all three AVGs for forehands and backhands. Kinect had a significantly larger hand path distance the two other AVGs for forehands and backhands. Wii and Move were found to not be significantly different in both forehands and backhands.

Insert Table 3 here

Insert Figure 3a here

There was no significant difference in hand path duration between the four table tennis types for forehands and backhands.

For both average speed and maximum speed there was a significant main effect for 'table tennis type' in both forehands and backhands (Figure 3b). Real table tennis had a significantly slower speed than all three AVGs for forehands and backhands. Kinect had a significantly faster speed than the two other AVGs for forehands and backhands. Wii and Move were found to not be significantly different in both forehands and backhands. 
For forehands the time of maximum speed was significantly later in Real than Move and Kinect (Appendix B). There was no significant difference within AVGs for forehands, nor between any of the four 'table tennis type' for backhands.

Insert Figure 3b here

\section{Discussion}

This study is the first to assess the fidelity of AVGs by comparing movement kinematics between virtual reality and real world table tennis. Movement kinematics during virtual table tennis were demonstrated to significantly differ from those during real world table tennis. Real world table tennis resulted in a significantly smaller wrist angle range, elbow angle range, hand path distance, average speed and maximum speed than all three AVGs (Nintendo Wii, Xbox Kinect, Sony Move) for both forehand and backhand strokes. This suggests that the differences in task constraints between the AVG and real world table tennis are sufficient that measureable kinematic performance change is required (Davids, et al., 2008a).

The differences in kinematics is not surprising given the obvious differences in task constraints between the real world table tennis and AVG table tennis tasks: in particular the display and input differences. There may be a number of critical non-modifiable differences in task and environmental constraints between AVG and the real world. For example, previous research has highlighted that perceptions and timing of ball movement (bounce and spin) and opposition player movements are critical in ball sports (Abernethy, 1993; Muller \& Abernethy, 2012). Therefore, the considerable differences in the displayed view of the opposition player and ball (i.e three dimensional real world players with physical ball strike versus two dimensional avatar and a ball that remains within a screen several meters from the player's 'bat') are certainly constraint differences that may impact on performance. The results of this study suggest that in order for players to achieve success (strike the ball) they varied their upper limb kinematics from real world movements. Whilst the specificity of learning hypothesis (M. L. Barnett, et al., 1973) suggests that skill transfer will not be optimal when practiced movement differs, what is not clear is whether these differences will result in substantial loss of skill transfer.

Although transfer of learning ideas generally agree that task similarities must exist for task transfer (Newell, 1989; Thorndike \& Woodworth, 1901), the magnitude of the 
similarities required for effective task transfer is unclear (Abernethy, 1993). Indeed, it may be that the AVG table tennis movements, while spatially and temporally different, share enough processing similarities that real world skill performance will still improve. Prior research directed at transfer of skill suggests that constraints and movement do not need to be identical. For example, positive transfer of perceptual information and strategies were reported between two sports with obvious constraint differences; hockey and soccer (Smeeton, Ward, \& Williams, 2004). It has also been reported that gymnasts have a positive transfer to swimming tasks (Collard, Oboeuf, \& Ahmaidi, 2007). Similar elements shared by AVG and real world table tennis included cognitive planning to anticipate the flight path of the ball and decisions whether to perform a forehand or a backhand (Farrow \& Anbernethy, 2003). Environmental elements, such as one versus one play, standard table tennis rules and match play to 11 points, were also similar between the AVGs and real world (Rosalie \& Muller, 2012). Hence there may be enough underlying similarity between the AVGs and real world tasks to allow for some transfer of learning and development of gross motor skills. This is supported by previous studies demonstrating that balance training on the Wii Fit (Nintendo, Kyoto, Japan) device could improve balance performance in people with impaired balance and cerebral palsy (Hammond, Jones, Hill, Green, \& Male, 2014; D. Jelsma, et al., 2014; J. Jelsma, et al., 2013).

There is a gap in knowledge regarding which key constraint elements contribute to AVG fidelity and therefore optimal transfer of skills (Taylor, McCormick, Shawis, Impson, \& Griffin, 2011). The results of the current study suggest there are constraints that can be modified to enhance AVG fidelity as there were differences in kinematics between the three AVG consoles. When playing on the Kinect, participants utilised a significantly larger and faster hand path compared to the real world and the other two AVGs. This result points to the importance of the use of a hand held 'bat', given the Kinect was the only AVG to not require a hand held control device. Despite the substantial differences between the table tennis bat and the Move and Wii control devices (such as dimension, grip type and mass), the results indicate that the proprioceptive input from holding a 'bat' in the hand is important. It is therefore likely that simulation of sports that include a hand held implement (e.g bat, racket, stick) is facilitated by an AVG hand held input control, in accordance with transfer of learning ideas (M. L. Barnett, et al., 1973). However, given there are other features that differ between AVG types (including avatar characteristics, dimensions, and movement speed), future research should focus on determining which elements (e.g. visual perspective, 
controller, ball strike modeling) could be improved so that the fidelity of AVG, and thus the likelihood of development of gross motor skills, is enhanced (Abernethy, 1993). Further research could also compare the efficacy of training regimens utilizing different design elements.

Some of the strengths of the current study included: a sample that represented a normal population of children at the peak age of electronic game use, the use of accessible and affordable AVGs and movement analyzed using a highly precise 3D system. Some study limitations were that: only one upper limb task was examined, only variables from the distal upper limb were assessed, game success rate was not examined, different levels of virtual and real table tennis expertise were not assessed and only simple kinematics measures (such as range of motion) were examined rather than more complex measures (such as sequencing, direction and variability of movement).

\section{Conclusion}

This study examined the potential for AVGs to help improve gross motor skill development by exploring the fidelity of AVGs for an example upper limb task - table tennis.

Improvements in gross motor skills via AVG play may provide an indirect pathway to break the cycle between poor motor skills and low PA participation if they can provide adequate task Iconstraint fidelity. Differences in upper limb kinematics where found between virtual table tennis and real world table tennis, suggesting that transfer of learning from virtual to real world tasks may be impaired. Future research should examine whether virtual and real world table tennis share enough similar constraint elements to allow for some transfer of learning. If AVG skills are transferable to real world activities, they can be promoted to a wide population of children as a viable means to enhance the development of motor skills and thus promote participation in PA.

\section{Acknowledgements}

The authors would like to acknowledge the children who participated and Paul Davey for data processing assistance. 


\section{References}

Abernethy, B. (1993). Searching for the minimal essential information for skilled perception and action. [Research Support, Non-U.S. Gov't]. Psychological research, 55(2), 131138.

Australian Bureau of Statistics (2012) Children's Participation in Cultural and Leisure Activities. (Catalogue no. 4901.0) Canberra, Australia: Australian Bureau of Statistics

Australian Government Department of Health and Ageing (2010) Physical Activity Guidelines.

Ackerman, P. L., \& Cianciolo, A. T. (2002). Ability and task constraint determinants of complex task performance. [Research Support, U.S. Gov't, Non-P.H.S.]. Journal of experimental psychology. Applied, 8(3), 194-208.

Barnett, L. M., Hardy, L. L., Lubans, D. R., Cliff, D. P., Okely, A. D., Hills, A. P., \& Morgan, P. J. (2013). Australian children lack the basic movement skills to be active and healthy. Health promotion journal of Australia : official journal of Australian Association of Health Promotion Professionals, 24(2), 82-84. doi: 10.1071/HE12920

Barnett, M. L., Ross, D., Schmidt, R. A., \& Todd, B. (1973). Motor skills learning and the specificity of training principle. Research quarterly, 44(4), 440-447.

Campbell, A., \& Alderson, J. (2009). Effects of differet technical coordinate system definitions on the three dimensional representation of the glenohumeral joint centre. Medical and Biological Engineering and Computing, 47(5), 543-550.

Campbell, A., \& Lloyd, D. (2009). MRI development and validation of two new predictive methods of glenohumeral joint centre location identification and comparison with established techniques. Journal of Biomechanics, 42(10), 1527-1532.

Cappozzo, A., Catani, F., Croce, U. D., \& Leardini, A. (1995). Position and orientation in space of bones during movement: anatomical frame definition and determination. Clinical biomechanics, 10(4), 171-178.

Collard, L., Oboeuf, A., \& Ahmaidi, S. (2007). Motor skills transfer from gymnastics to swimming. Perceptual Motor Skills, 105(1), 15-26.

Davids, K., Button, C., \& Bennett, S. (2008a). Dynamics of Skill Acquisition: a ConstraintsLed Approach. International Journal of Sports Science and Coaching, 3(1), 147-152.

Davids, K., Button, C., \& Bennett, S. (2008b). Dynamics of Skill Acquisition: a ConstraintsLed Approach. International Journal of Sports Science and Coaching, 3(1), 147-152.

Ehara, Y., Fujimoto, H., Miyazaki, S., Tanaka, S., \& Yamamoto, S. (1995). Comparison of the performance of 3D camera systems. . Gait and Posture, 3(3), 166-169.

Farrow, D., \& Anbernethy, B. (2003). Do expertise and the degree of perception-action coupling affect natural anticipatory performance? Perception, 32(9), 1127-1139.

Hammond, J., Jones, V., Hill, E. L., Green, D., \& Male, I. (2014). An investigation of the impact of regular use of the Wii Fit to improve motor and psychosocial outcomes in children with movement difficulties: a pilot study. [Research Support, Non-U.S. Gov't]. Child: care, health and development, 40(2), 165-175. doi: 10.1111/cch.12029

Henderson, S., Sugden, D., \& Barnet, A. (2007). Movement Assessment Battery for Children2 Examiners Manual. London: Pearson Assessment.

Janz, K. F., Letuchy, E. M., Eichenberger Gilmore, J. M., Burns, T. L., Torner, J. C., Willing, M. C., \& Levy, S. M. (2010). Early physical activity provides sustained bone health benefits later in childhood. [Research Support, N.I.H., Extramural]. Medicine \& Science in Sports \& Exercise, 42(6), 1072-1078.

Jelsma, D., Geuze, R. H., Mombarg, R., \& Smits-Engelsman, B. C. (2014). The impact of Wii Fit intervention on dynamic balance control in children with probable 
Developmental Coordination Disorder and balance problems. Human Movement Science, 33, 404-418. doi: 10.1016/j.humov.2013.12.007

Jelsma, J., Pronk, M., Ferguson, G., \& Jelsma-Smit, D. (2013). The effect of the Nintendo Wii Fit on balance control and gross motor function of children with spastic hemiplegic cerebral palsy. [Randomized Controlled Trial

Research Support, Non-U.S. Gov't]. Developmental neurorehabilitation, 16(1), 27-37. doi: 10.3109/17518423.2012.711781

Levac, D., Pierrynowski, M. R., Canestraro, M., Gurr, L., Leonard, L., \& Neeley, C. (2010). Exploring children's movement characteristics during virtual reality video game play. Human movement science, 29(6), 1023-1038. doi: 10.1016/j.humov.2010.06.006

Lloyd, M., Saunders, T. J., Bremer, E., \& Tremblay, M. S. (2014). Long-term importance of fundamental motor skills: a 20-year follow-up study. Adapted physical activity quarterly : APAQ, 31(1), 67-78. doi: 10.1123/apaq:2013-0048

McKenzie, T., Alcaraz, A., \& Sallis, J. (1998). Effects of physical education program on children's manipulative skill. Journal of Teaching in Physical Education(17), 327341.

Mitchinson, L., Campbell, A., Oldmeadow, D., Gibson, W., \& Hopper, D. (2012). Comparison of Upper Arm Kinematics During a Volleyball Spike Between Players With and Without a History of Shoulder Injury. Journal of applied biomechanics.

Muller, S., \& Abernethy, B. (2012). Expert anticipatory skill in striking sports: a review and a model. Research Quaterly for Exercise and Sport, 83(2), 175-187.

Newell, K. M. (1989). On task and theory specificity. Journal of motor behavior, 21(1), 9296.

Papastergiou, M. (2009). Exploring the potential of computer and video games for health and physical education: A literature review. Computers \&amp; Education, 53(3), 603622. doi: 10.1016/j.compedu.2009.04.001

Richards, J. (1999). The measurement of human motion: A comparison of comercially available systems. Human Movement Science, 18, 589-602.

Rideout, V., Foehr, U., \& Roberts, D. (2010). Generation M2: Media in the lives of 8-to 18Year-Olds. California: Kaiser Family Foundation.

Rosalie, S., \& Muller, S. (2012). A model for the transfer of perceptual-motor skill learning in human behaviours. Research Quarterly for Exercise and Sport, 83, 412-421.

Rose, F. D., Attree, E. A., Brooks, B. M., Parslow, D. M., Penn, P. R., \& Ambihaipahan, N. (2000). Training in virtual environments: transfer to real world tasks and equivalence to real task training. [Comparative Study

Research Support, Non-U.S. Gov't]. Ergonomics, 43(4), 494-511. doi: 10.1080/001401300184378

Smeeton, N. J., Ward, P., \& Williams, A. M. (2004). Do pattern recognition skills transfer across sports? A preliminary analysis. Journal of Sports Sciences, 22(2), 205-213. doi: 10.1080/02640410310001641494

Straker, L., Campbell, A., Jensen, L., Metcalf, D., Smith, A., Abott, R., . . Piek, J. (2011). Rationale, design and methods for a randomised and controlled trial of the impact of virtual reality games on motor competence, physical activity, and mental health in children with developmental coordination disorder. BMC Public Health, 11(654).

Taylor, M. P., McCormick, D. B., Shawis, T. M. F., Impson, R. M., \& Griffin, M. P. (2011). Activity-promoting gaming systems in exercise and rehabilitation. Journal of Rehabilitation Research and Development, 48(10), 1171.

Thorndike, E. L., \& Woodworth, R. S. (1901). The influence of improvement in one mental function upon teh efficiency of other functions. Psychological Reviews, 8, 247-261. 
Woltering, H. (1986). A fortran package for generalized, cross-validatory sline smooting and differentiation. Advances in Engineering and Software, 8(2), 104-113.

Wu, G., van der Helm, F. C. T., Veeger, H. E. J., Makhsous, M., Van Roy, P., Anglin, C., ... Buchholz, B. (2005). ISB recommendation on definitions of joint coordinate systems of various joints for the reporting of human joint motion-Part II: shoulder, elbow, wrist and hand. Journal of Biomechanics, 38(5), 981-992. doi:

10.1016/j.jbiomech.2004.05.042 


\section{List of Tables and Figures}

Table 1. Wrist angles during forehand and backhand strokes by children playing AVG and Real table tennis

Table 2. Elbow angles during forehand and backhand strokes by children playing AVG and Real table tennis

Table 3. Hand temporal and spatial values during forehand and backhand strokes by children playing AVG and Real table tennis

Figure 1. Wrist angle range during forehand and backhand strokes by children playing AVG and Real table tennis, represented as Mean with Standard Deviation Error Bars

Figure 2 Elbow range during forehand and backhand strokes by children playing AVG and Real table tennis, represented as Mean with Standard Deviation Error Bars

Figure 3a. Path distance during forehand and backhand strokes by children playing AVG and Real table tennis, represented as Mean with Standard Deviation Error Bars

Figure $3 b$. Average speed during forehand and backhand strokes by children playing AVG and Real table tennis, represented as Mean with Standard Deviation Error Bars 
Table 1. Wrist Angles during forehand and backhand strokes by children playing AVG and Real table tennis

\begin{tabular}{|c|c|c|c|c|c|}
\hline $\begin{array}{l}\text { Wrist Angle } \\
\text { Variable }\end{array}$ & Kinect & Move & Wii & Real & $\begin{array}{l}\text { P value } \\
\text { (main } \\
\text { effect) }\end{array}$ \\
\hline \multicolumn{6}{|c|}{ Forehand } \\
\hline \multirow[t]{2}{*}{ Range } & 51.45 & 48.32 & 51.05 & 28.62 & $<0.001$ \\
\hline & $(28.10)^{\mathrm{a}}$ & $(25.91)^{\mathrm{a}}$ & $(24.76)^{\mathrm{a}}$ & $(14.33)^{b}$ & \\
\hline \multirow[t]{2}{*}{ Maximum } & 18.8 & 19.0 & 17.5 & 0.57 & $<0.001$ \\
\hline & $(20.3)^{\mathrm{a}}$ & $(19.4)^{\mathrm{a}}$ & $(21.3)^{\mathrm{a}}$ & $(18.8)^{\mathrm{b}}$ & \\
\hline \multirow[t]{2}{*}{ Minimum } & -32.13 & -30.11 & -33.53 & -27.93 & 0.760 \\
\hline & $(32.95)^{\mathrm{a}}$ & $(31.96)^{\mathrm{a}}$ & $(33.64)^{\mathrm{a}}$ & $(23.45)^{\mathrm{a}}$ & \\
\hline \multicolumn{6}{|c|}{ Backhand } \\
\hline \multirow[t]{2}{*}{ Range } & 39.65 & 47.24 & 37.23 & 18.52 & $<0.001$ \\
\hline & $(21.65)^{\mathrm{a}}$ & $(25.20)^{\mathrm{a}}$ & $(21.50)^{\mathrm{a}}$ & $(10.14)^{b}$ & \\
\hline \multirow[t]{2}{*}{ Maximum } & 17.29 & 23.14 & 17.02 & 13.04 & 0.230 \\
\hline & $(23.87)^{\mathrm{ab}}$ & $(24.82)^{\mathrm{a}}$ & $(31.06)^{\mathrm{ab}}$ & $(28.09)^{b}$ & \\
\hline \multirow[t]{2}{*}{ Minimum } & -22.50 & -28.88 & -20.21 & -5.48 & 0.023 \\
\hline & $(25.83)^{\mathrm{a}}$ & $(24.58)^{\mathrm{a}}$ & $(33.39)^{\mathrm{ab}}$ & $(26.59)^{b}$ & \\
\hline
\end{tabular}


Table 2. Elbow Angles during forehand and backhand strokes by children playing AVG and Real table tennis

\begin{tabular}{|c|c|c|c|c|c|}
\hline $\begin{array}{l}\text { Elbow Angle } \\
\text { Variable }\end{array}$ & Kinect & Move & Wii & Real & $\begin{array}{c}\text { P value } \\
\text { (main effect) }\end{array}$ \\
\hline \multicolumn{6}{|c|}{ Forehand } \\
\hline Range & $\begin{array}{l}63.27 \\
\left(23.96^{\mathrm{a}}\right.\end{array}$ & $\begin{array}{l}64.22 \\
(19.95)^{\mathrm{a}}\end{array}$ & $\begin{array}{l}64.20 \\
(18.67)^{\mathrm{a}}\end{array}$ & $\begin{array}{l}45.01 \\
\left(17.86^{b}\right.\end{array}$ & 0.006 \\
\hline Maximum & $\begin{array}{l}96.78 \\
(32.81)^{\mathrm{a}}\end{array}$ & $\begin{array}{l}107.10 \\
(28.73)^{\mathrm{a}}\end{array}$ & $\begin{array}{l}109.87 \\
\left(30.16^{\mathrm{a}}\right.\end{array}$ & $\begin{array}{l}96.32 \\
\left(16.32^{a}\right.\end{array}$ & 0.168 \\
\hline Minimum & $\begin{array}{l}31.50 \\
(23.95)^{\mathrm{a}}\end{array}$ & $\begin{array}{l}41.26 \\
(19.58)^{b}\end{array}$ & $\begin{array}{l}42.94 \\
(22.44)^{b}\end{array}$ & $\begin{array}{l}49.09 \\
(21.83)^{b}\end{array}$ & 0.018 \\
\hline & & & and & & \\
\hline Range & $\begin{array}{l}85.34 \\
(29.44)^{\mathrm{a}}\end{array}$ & $\begin{array}{l}71.99 \\
(27.89)^{\mathrm{a}}\end{array}$ & $\begin{array}{l}75.01 \\
(36.35)^{\mathrm{a}}\end{array}$ & $\begin{array}{l}48.63 \\
(20.17)^{b}\end{array}$ & $<0.001$ \\
\hline Maximum & $\begin{array}{l}101.53 \\
(27.65)^{\mathrm{a}}\end{array}$ & $\begin{array}{l}99.83 \\
(24.79)^{\mathrm{a}}\end{array}$ & $\begin{array}{l}98.44 \\
(17.94)^{\mathrm{a}}\end{array}$ & $\begin{array}{l}108.29 \\
(25.75)^{\mathrm{a}}\end{array}$ & 0.370 \\
\hline Minimum & $\begin{array}{l}11.49 \\
(21.81)^{\mathrm{a}}\end{array}$ & $\begin{array}{l}24.58 \\
(25.70)^{b}\end{array}$ & $\begin{array}{l}22.76 \\
(20.40)^{b}\end{array}$ & $\begin{array}{l}55.29 \\
(21.55)^{\mathrm{c}}\end{array}$ & $<0.001$ \\
\hline
\end{tabular}

Data is represented as Mean (Standard Deviation) Elbow Angles are measured in degrees of motion $\left(^{\circ}\right)$

Values sharing the same superscript are not significantly different (pairwise comparison $\mathrm{p}<0.01$ ). 
Table 3. Hand temporal and spatial values during forehand and backhand strokes by children playing AVG and Real table tennis

\begin{tabular}{|c|c|c|c|c|c|}
\hline Variable & Kinect & Move & Wii & Real & $\begin{array}{l}\text { P value } \\
\text { (main effect) }\end{array}$ \\
\hline \multicolumn{6}{|c|}{ Forehand } \\
\hline Path & 1.64 & 1.24 & 1.21 & 0.71 & $<0.001$ \\
\hline Distance & $(0.58)^{\mathrm{a}}$ & $(0.48)^{\mathrm{b}}$ & $(0.35)^{\mathrm{b}}$ & $(0.21)^{\mathrm{c}}$ & \\
\hline Path & 0.49 & 0.52 & 0.54 & 0.51 & 0.554 \\
\hline Duration & $(0.13)^{\mathrm{a}}$ & $(0.14)^{\mathrm{a}}$ & $(0.11)^{\mathrm{a}}$ & $(0.10)^{\mathrm{a}}$ & \\
\hline Average & 3.34 & 2.42 & 2.30 & 1.36 & $<0.001$ \\
\hline Speed & $(0.84)^{\mathrm{a}}$ & $(0.83)^{b}$ & $(0.49)^{\mathrm{b}}$ & $(0.51)^{\mathrm{c}}$ & \\
\hline Maximum & 6.98 & 5.01 & 5.17 & 2.47 & $<0.001$ \\
\hline Speed & $(1.39)^{\mathrm{a}}$ & $(1.35)^{\mathrm{b}}$ & $(0.96)^{b}$ & $(0.96)^{\mathrm{c}}$ & \\
\hline Time of & 0.21 & 0.22 & 0.23 & 0.26 & 0.079 \\
\hline Max Speed & $(0.07)^{\mathrm{a}}$ & $(0.08)^{\mathrm{a}}$ & $(0.08)^{\mathrm{ab}}$ & $(0.09)^{\mathrm{b}}$ & \\
\hline \multicolumn{6}{|c|}{ Backhand } \\
\hline Path & 1.54 & 1.22 & 1.08 & 0.59 & $<0.001$ \\
\hline Distance & $(0.62)^{\mathrm{a}}$ & $(0.64)^{\mathrm{b}}$ & $(0.55)^{b}$ & $(0.18)^{\mathrm{c}}$ & \\
\hline Path & 0.50 & 0.50 & 0.47 & 0.44 & 0.164 \\
\hline Duration & $(0.11)^{\mathrm{a}}$ & $(0.14)^{\mathrm{a}}$ & $(0.14)^{\mathrm{a}}$ & $(0.07)^{\mathrm{a}}$ & \\
\hline Average & 3.07 & 2.33 & 2.18 & 1.29 & $<0.001$ \\
\hline Speed & $(0.81)^{\mathrm{a}}$ & $(0.73)^{\mathrm{b}}$ & $(0.58)^{\mathrm{b}}$ & $(0.30)^{\mathrm{c}}$ & \\
\hline Maximum & 5.92 & 4.69 & 4.20 & 2.18 & $<0.001$ \\
\hline Speed & $(1.28)^{\mathrm{a}}$ & $(1.35)^{\mathrm{b}}$ & $(0.94)^{b}$ & $(0.69)^{\mathrm{c}}$ & \\
\hline Time of & 0.21 & 0.20 & 0.18 & 0.20 & 0.198 \\
\hline Max Speed & $(0.05)^{\mathrm{a}}$ & $(0.06)^{\mathrm{a}}$ & $(0.08)^{\mathrm{a}}$ & $(0.05)^{\mathrm{a}}$ & \\
\hline
\end{tabular}

Data is represented as Mean (Standard Deviation)

Duration is measured in seconds ( $\mathrm{s}$ ). Speed is measured as metres per second $\left(\mathrm{ms}^{-1}\right)$. Time of Maximum Speed is measured as time in (s) from the initiation of forehand/backhand, Path Distance is measured in metres (m) Values sharing the same superscript are not significantly different (pairwise comparison $\mathrm{p}<0.01$ ).

Figure 1. Wrist Angle Range during forehand and backhand strokes by children playing AVG and Real table tennis, represented as Mean with Standard Deviation Error Bars 


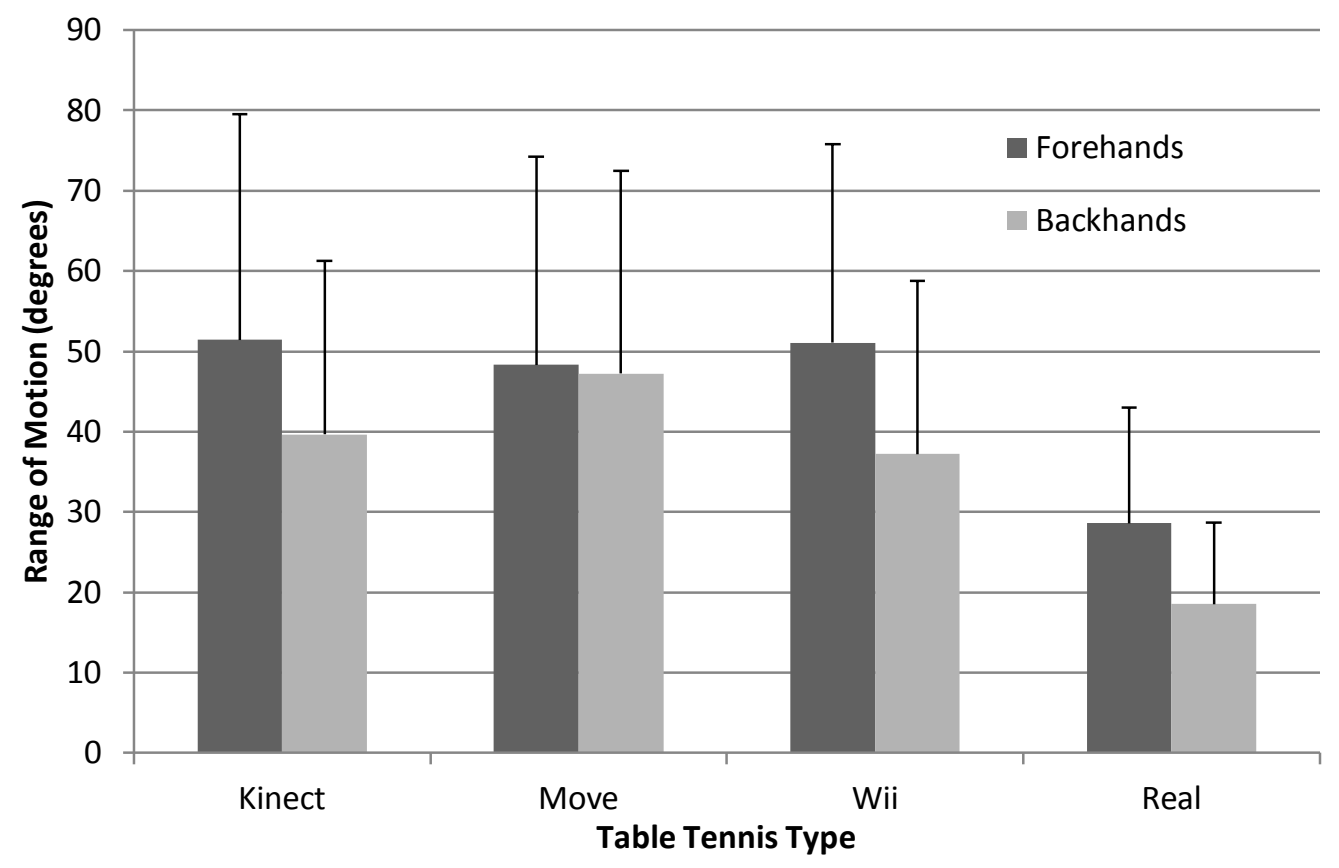

Note: Real table tennis required significantly less wrist range of motion than the three AVG's for both forehands and backhands. See table 1 for further details. 
Figure 2. Elbow Range during forehand and backhand strokes by children playing AVG and Real table tennis, represented as Mean with Standard Deviation Error Bars

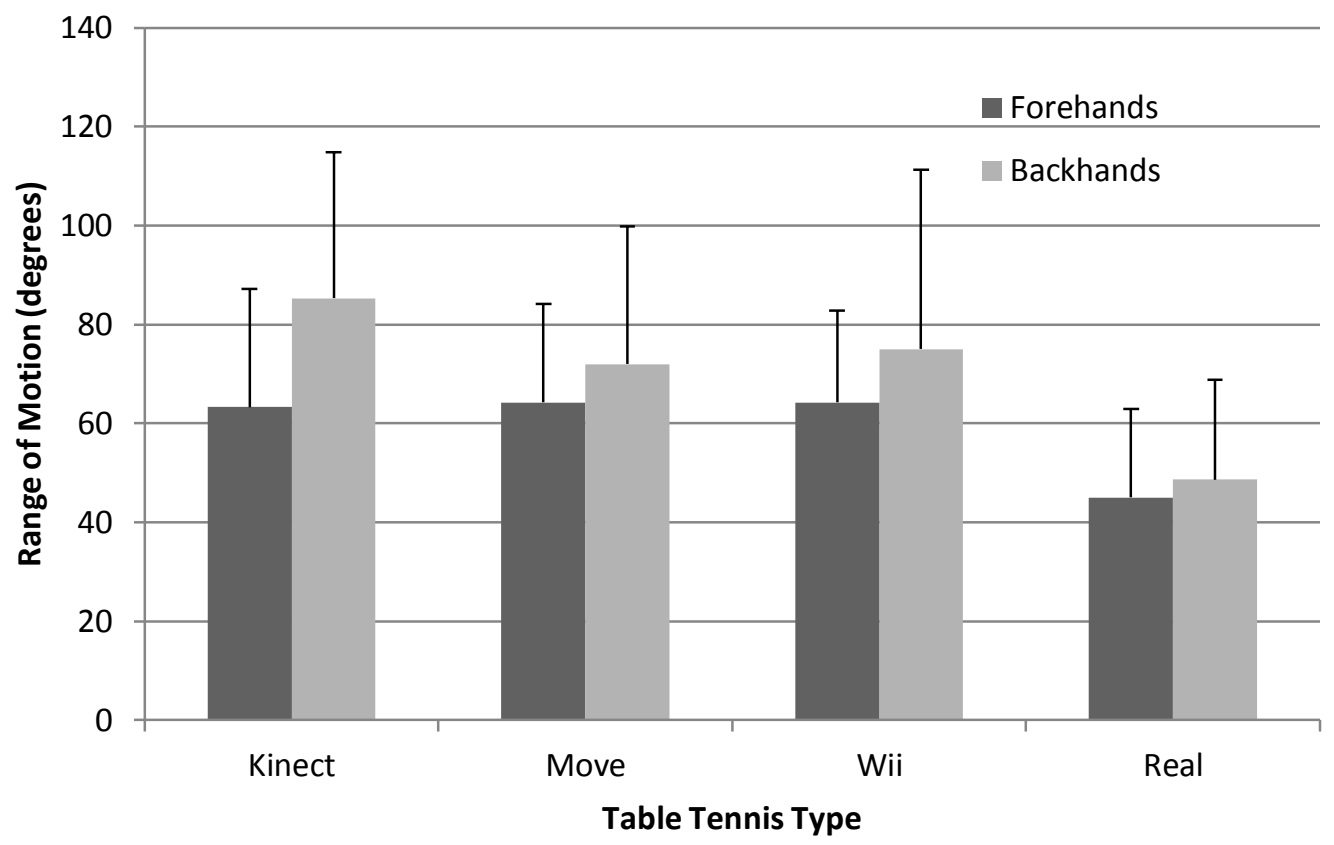

Note: Real table tennis required significantly less elbow range of motion than the three $A V G$ 's for both forehands and backhands. See table 2 for further details. 
Figure 3a. Hand Path Distance during forehand and backhand strokes by children playing AVG and Real table tennis, represented as Mean with Standard Deviation Error Bars

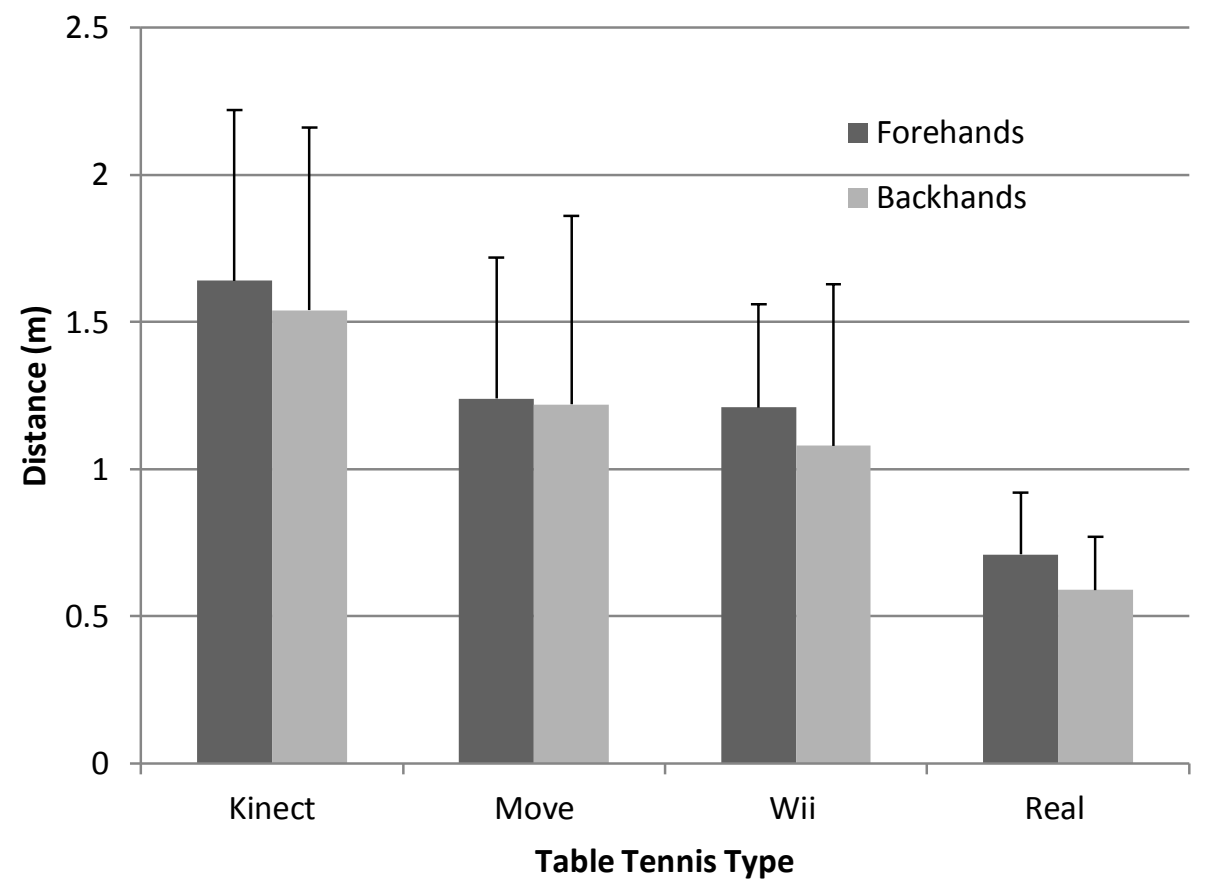

Note: Real table tennis required significantly less hand movement than the three AVG's for both forehands and backhands. Further, the Kinect required significantly more hand movement than the Move and Wii. See table 3 for further details. 
Figure 3b. Average Hand Speed during forehand and backhand strokes by children playing AVG and Real table tennis, represented as Mean with Standard Deviation Error Bars

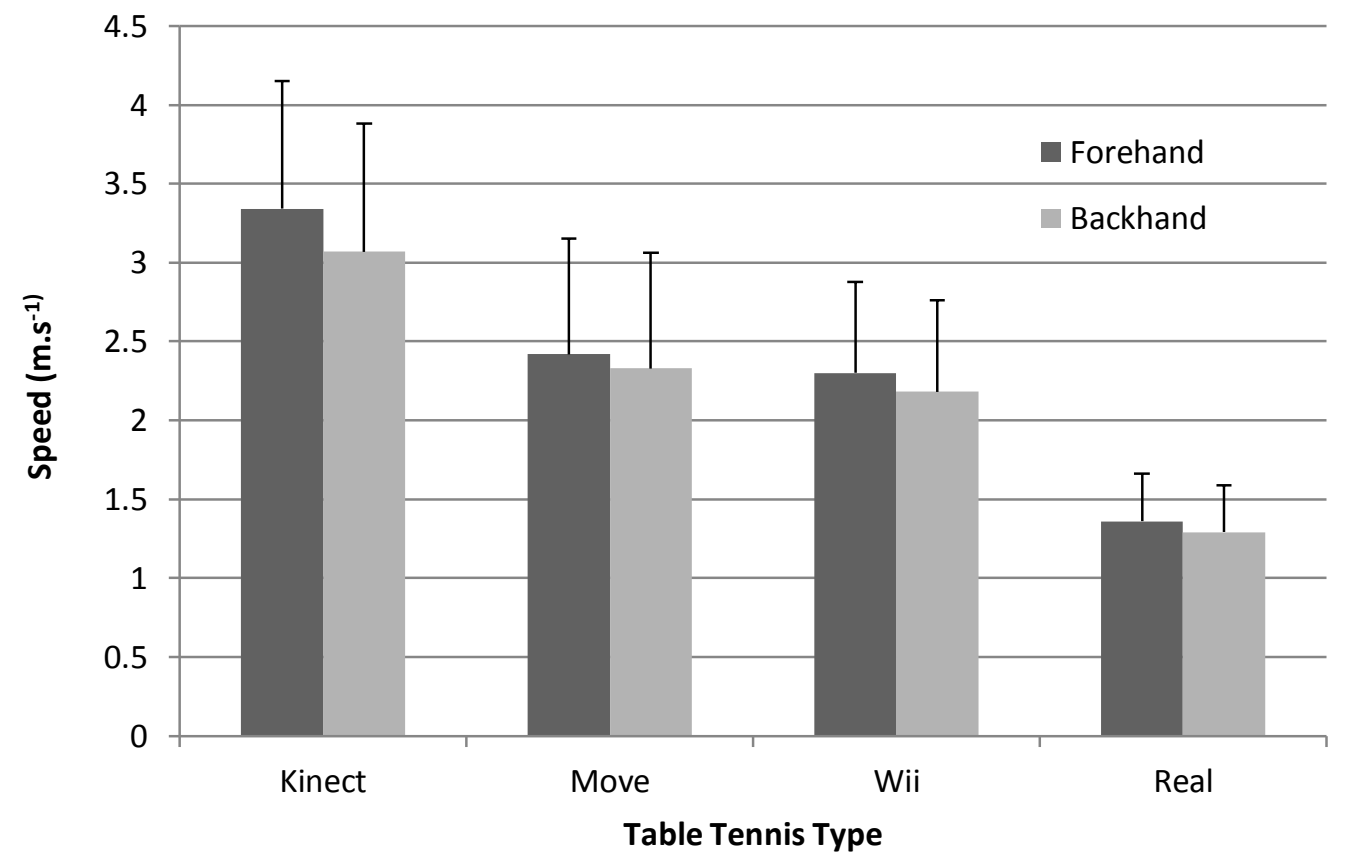

Note: Real table tennis required significantly slower hand speed than the three AVG's for both forehands and backhands. Further, the Kinect required significantly faster hand speed than the Move and Wii. See table 3 for further details. 